\title{
DIÁLOGOS JURISDICIONAIS E CONTROLE DE CONVENCIONALIDADE: DESAFIOS À HARMONIZAÇÃO DO DIÁLOGO ENTRE A CORTE INTERAMERICANA DE DIREITOS HUMANOS E AS JURISDIÇÕES NACIONAIS LATINO- AMERICANAS EM TEMPOS DE NEOCONSTITUCIONALISMO
}

Thaís Bordin Anelli ${ }^{329}$

Recebido em: 24/11/2016

Aprovado em: 15/05/2017

\section{RESUMO}

A presente pesquisa enfrenta a problemática dos desafios à harmonização do diálogo jurisdicional entre a Corte Interamericana de Direitos Humanos e as jurisdições nacionais latino-americanas, no contexto do neoconstitucionalismo. Para tanto, elegeu-se o método de abordagem hermenêutico-fenomenológico, uma vez que com a incursão do intérprete no fenômeno ocorre a compreensão. Desse modo, os fenômenos estudados são os diálogos entre a Corte IDH e as jurisdições nacionais com o mecanismo do controle de convencionalidade nessa conversa. Assim, como procedimento é adotada a revisão bibliográfica e documental. Ainda, divide-se a pesquisa em três fases, na primeira serão avaliados os aspectos contextuais, bem como a conceituação dos diálogos jurisdicionais e as perspectivas harmonizantes e dissonantes desses diálogos. Na segunda etapa, os aportes doutrinários acerca do controle de convencionalidade são elencados, busca-se, assim, as lições de Humberto Nogueira Alcalá, Eduardo Ferrer Mac-Gregor, Valerio Mazzuoli, Flávia Piovesan, dentre outros. E na última etapa, é apresentado o alinhamento das ideias dos diálogos jurisdicionais e o controle de convencionalidade enquanto ferramenta de harmonização entre fontes internas e convencionais, e ainda, quais os desafios restantes para a efetivação desse controle nos diálogos, em período de internacionalização do direito.

Palavras-chave: Diálogos jurisdicionais. Controle de convencionalidade. Neoconstitucionalismo.

\footnotetext{
${ }^{329}$ Mestranda pelo Programa de Pós-Graduação Stricto Sensu - Mestrado em Direito pela Universidade Federal de Santa Maria (UFSM). Especialista em Direito Tributário pela Universidade Anhanguera - UNIDERP/RS. Bacharela em Direito pela Faculdade de Direito de Santa Maria - FADISMA/RS. Advogada.
} 


\section{INTRODUÇÃO}

Os novos aspectos da contemporaneidade trazem mudanças inclusive no direito. Há múltiplas intersecções do direito internacional no direito nacional que causam problemas constitucionais. Nesse ponto, como pano de fundo da presente pesquisa, o neoconstitucionalismo demonstra soluções para esses problemas constitucionais.

Assim, das intersecções do direito internacional com o nacional surgem os diálogos jurisdicionais e o mecanismo do controle de convencionalidade vem como uma ferramenta de harmonização das normas nacionais com as normas convencionais. Nessa perspectiva, nesse estudo será avaliada como problemática os desafios à harmonização do diálogo jurisdicional entre a Corte Interamericana de Direitos Humanos e as jurisdições nacionais latino-americanas.

Para desenvolvimento dessa análise, optou-se pela abordagem hermenêuticafenomenológica, pois essa abordagem se dá pela inserção do intérprete no contexto dos fatos, para obtenção de sentido, de compreensão. E o método de procedimento eleito é o da revisão bibliográfica.

Então, essa pesquisa será dividida em três etapas. Na primeira delas, serão abordados os delineamentos contextuais do tema. Desse modo, o contexto do neoconstitucionalismo será trazido, bem como reflexões do diálogo entre jurisdições e as perspectivas harmonizantes e dissonantes resultantes dessa conversa.

Na segunda fase da pesquisa, serão demonstrados os aspectos doutrinários acerca do controle de convencionalidade. Assim, elencam-se as lições de Humberto Nogueira Alcalá, Eduardo Ferrer Mac-Gregor, Valerio Mazzuoli, Flávia Piovesan, dentre outros. Nessa etapa da pesquisa, serão inferidos também os efeitos do controle de convencionalidade.

$\mathrm{Na}$ terceira e última fase da pesquisa, a sincronização das ideias dos diálogos jurisdicionais e o controle de convencionalidade será avaliada. E ainda, serão apresentados os desafios às jurisdições na contemporaneidade para efetivação de diálogos jurisdicionais auxiliados pelo exercício do controle de convencionalidade a fim de que se tutelem os direitos humanos, em período de internacionalização do direito. Assim, demarcadas as linhas iniciais, passa-se à exposição do tema.

\section{O DESENHAR DOS DIÁLOGOS JURISDICIONAIS EM TEMPOS DE NEOCONSTITUCIONALISMO}


Vivencia-se na contemporaneidade um ambiente de trocas, comunicações e fronteiras flexibilizadas. Colhendo a noção das "membranas plasmáticas" da Biologia para o Direito, percebe-se que essas estão cada vez mais permeáveis, o que permite constantemente trocas e aberturas. O meio interno com o meio externo, do Direito nacional com o internacional e vicee-versa.

Essas aberturas buscam a efetivação da internacionalização do direito através do diálogo judicial, que conforme infere Laurence Burgorgue-Larsen, esse diálogo "acontece num espaço em que as fronteiras territoriais, como as culturais, as linguísticas, as societais, recuam sempre cada vez mais" (BURGORGUE-LARSEN, 2010, p. 263).

Desse modo, como ensina Mireille Delmas-Marty, o movimento da internacionalização dos juízes nacionais começa pela intensificação dos intercâmbios entre magistrados, facilitada pelas novas tecnologias de informação e pela criação de redes judiciais, por uma tradução livre $^{330}$, (DELMAS-MARTY, 2007, p. 42)

Nesse sentido, dessas trocas e aberturas resultam em diálogos que na presente pesquisa são concebidos como diálogos jurisdicionais, como ensina Daniel Sarmento, "há uma positiva troca de experiência, conceitos e ideias entre cortes nacionais e internacionais, com a possibilidade de aprendizado recíproco entre as instâncias envolvidas nesse diálogo" (SARMENTO, 2016, p. 121 e 122)

Essa troca de experiência, conceitos e ideias para o belga Benoît Frydman é encarada como a noção de citações que ocorrem em vários sentidos, para o autor existem as citações horizontais, entre jurisdições de mesmo nível, como exemplo entre cortes constitucionais ou entre o sistema europeu e o interamericano de direitos humanos. Também existem as citações verticais, configuradas por níveis diferentes, são as citações de "de baixo para cima" ou de "cima para baixo", quando uma corte nacional cita uma corte internacional, ou quando a corte internacional elenca a corte nacional, respectivamente. No mais, pode acontecer as citações cruzadas, quando uma ordem de direitos humanos cita uma ordem de mercado, por exemplo (FRYDMAN, 2016, p. 20).

Vale destacar ainda, os ensinamentos de Laurence Burgorgue-Larsen ao mencionar sobre a categoria de diálogos soltos. Nesse sentido, para o autor há diálogo solto quando os

\footnotetext{
${ }^{330}$ Do original em Francês, "Le mouvement commence par une intensification des échanges entre juges, facilitée par les nouvelles technologies de l'information et par la mise en place de réseaux judiciaires" (DELMAS-MARTY, 2007, p. 42)
} 
magistrados se comunicam sem obrigação sistêmica, por exemplo, com traços de espontaneidade. Nas palavras de Burgorgue-Larsen, “o juiz que dialoga assim com outros juízes, sem nenhuma obrigação para fazê-lo, encontra-se, na realidade, inserido numa rede de vinculações mais ou menos exigentes" (BURGORGUE-LARSEN, 2010, p. 286).

Também, por outra classificação é possível estabelecer quatro modalidades de diálogos jurisdicionais, de acordo com Flávia Piovesan, essas vertentes são concebidas sob uma perspectiva multinível: $1^{\circ}$ diálogo com o sistema global, pelo qual há incorporação de parâmetros protetivos de direitos humanos; $2^{\circ}$ diálogo entre sistemas regionais, no qual envolve “a 'europeicização' do sistema interamericano e a 'interamericanização' do sistema europeu”; $3^{\circ}$ diálogo com os sistemas nacionais, pelo qual há o controle de convencionalidade, e $4^{\circ}$ diálogo com a sociedade civil que viabiliza "ao sistema interamericano crescente legitimação social" (PIOVESAN, 2013, p. 164 e 165).

Destaca-se que a terceira vertente de diálogo, qual seja: diálogo jurisdicionais com sistema nacional é que será estudado na segunda parte dessa pesquisa, em especial para o enfrentamento do problema de compatibilização de normas nacionais com as convencionais, através do controle de convencionalidade. Mas antes, serão tratados os aportes doutrinários sobre os diálogos jurisdicionais.

Esse fenômeno dos diálogos jurisdicionais, por vezes denominado de interjurisdicionais, está situado num contexto contemporâneo do constitucionalismo, o neoconstitucionalismo. E de acordo com as lições de Miguel Carbonell, esses novos tempos para o constitucionalismo não são estanques, são movimentos que ainda não se consolidaram e possuem uma série de problemas a equalizar (2009, p. 11). Nesse aspecto que se pensa no diálogo jurisdicional enquanto movimento neoconstitucional e a tentativa equalizadora do controle de convencionalidade.

A influência das normas, jurisprudência e doutrina estrangeira no ramo do direito constitucional é característica do neoconstitucionalismo. Dessa maneira, leciona Walter Claudius Rothenburg que "a diversidade de fontes do Direito externas e a análise da experiência jurídica alheia não devem conduzir a uma singela apropriação e imitação" (2014, p. 43). Até porque se houvesse a simples "apropriação" da fonte estrangeira não haveria a troca, não haveria conversação, diálogo, seria um monólogo.

Desse modo, ao tratar do neoconstitucionalismo, André de Carvalho Ramos ilustra que no cenário neoconstitucional, a interpretação das Constituições é vinculada aos princípios, bem como as normas constitucionais são irradiadas para os diversos ramos do direito 
(constitucionalização do direito), e ainda, aceita-se a abertura das Constituições às normas internacionais (diálogos jurisdicionais) (CARVALHO DE RAMOS, 2016, p. 445)

Sobre o diálogo entre as cortes nacionais e cortes regionais, André Ramos baseado nas lições de Gerald Neunam, infere que esses câmbios entre as cortes geram um pluralismo de ordens jurídicas e disso resultam em harmonias e dissonâncias. Com relação ao campo harmônico e seus reflexos, é possível se obter, então, alguns fenômenos, como: a) a abertura da ordem jurídica interna à internacional (normas convencionais e extraconvencionais); b) reconhecimento de um "bloco de constitucionalidade" composto por normas internacionais com hierarquia constitucional; c) utilização da ratio decidendi internacional para fundamentação das decisões nacionais, e d) influência nos avanços nacionais com relação à redação e interpretação ao Direito Internacional, com base em órgãos internacional de proteção dos direitos humanos (CARVALHO DE RAMOS, 2016, p. 447)

Com relação à abertura da ordem jurídica interna à internacional é preciso a utilização de mecanismos legislativos para que o tratado internacional seja incorporado ao ordenamento interno. No Brasil, essa adequação é vislumbrada pelos dispositivos 84, VIII, e 49, I, da Constituição Federal, nos quais demarcam a competência privativa do Presidente da República para celebrar tratados e convenções internacionais, com referendo do Congresso Nacional e a competência exclusiva do Congresso Nacional para resolver tratados internacionais que prejudiquem o patrimônio nacional, respectivamente (BRASIL, 1988).

Com referência ao segundo item harmônico dos diálogos jurisdicionais no viés nacional/regional internacional, tem-se o reconhecimento do "bloco de constitucionalidade" das normas internacionais com hierarquia constitucional. E no caso do Brasil, é preciso que se relembre da questão procedimental de incorporação de tratados internacionais. Assim, para essa internalização, após a Emenda Constitucional 45, de 8 de dezembro de 2004, a Constituição da República Federativa do Brasil, de 1988, foi alterada em seu artigo $5^{\circ}, \S^{\circ}$, para exigência de quórum qualificado para incorporar tratados internacionais de direitos humanos com status de emenda constitucional (BRASIL, 1988).

No que atine ao terceiro ponto harmônico dos diálogos jurisdicionais, sobre utilização da ratio decidendi internacional para fundamentação das decisões nacionais, se fortalece o uso retórico e argumentativo de razões de decidir com base em fonte internacional do direito para incrementar o poder de convencimento nas decisões. Exemplifica André Carvalho Ramos que essa fundamentação de decisão que bebe na fonte internacional pôde ser verificada, no Brasil, quando da desobrigação do diploma de Jornalismo aos profissionais do ramo. No voto do 
Ministro Relator Gilmar Mendes, a Opinião Consultiva $n^{\circ} 5$ da Corte Interamericana de Direitos Humanos foi amplamente empregada para a interpretação da Convenção Americana de Direitos Humanos (CARVALHO DE RAMOS, 2016, p. 453).

No mais, como quarto aspecto harmônico, sobre o uso das leis e decisões nacionais para influenciar a redação e interpretação do Direito Internacional, tem-se que os órgãos internacionais também estão abertos à recepção de novos marcos de proteção dos direitos humanos. Como exemplo, traz-se que a Corte Europeia de Direitos Humanos ao condenar o Reino Unido por violação à Convenção Europeia de Direitos Humanos, no caso Goodwin, fundamentou sua decisão com base em legislações nacionais de Holanda, Itália e Turquia sobre os direitos dos transexuais. Isso pois, Christiane Goodwin fez a cirurgia de mudança de sexo, entretanto o Reino Unido não considerou do sexo feminino para questões previdenciárias e cíveis, o que gerou a demanda perante à Corte Europeia (CARVALHO DE RAMOS, 2016, p. 453 e 454$)$.

Ressaltada as considerações do resultado harmônico dos diálogos jurisdicionais, passase a expor quanto às dissonâncias. Nesse sentido, André de Carvalho Ramos aduz que são três as modalidades de dissonância. A primeira está conectada ao fato de que por vezes os tratados internacionais são interpretados na esfera doméstica em desacordo com a interpretação internacional. E assim, utiliza-se a fonte internacional, mas com parâmetros interpretativos nacionais, o que gera a dissonância com a esfera internacional, por não ter sido apoiado em jurisprudência externa, quando da interpretação, por exemplo (CARVALHO DE RAMOS, 2016, p. 454).

E o segundo aspecto dissonante refere-se às decisões judiciais internas que invalidam tratados internacionais sem qualquer modulação temporal. Nesse ponto, no Brasil, quando há declaração de inconstitucionalidade nacional não se produz a automaticamente a invalidade internacional, o que pode ocasionar que o Estado brasileiro incorra em responsabilização internacional. De outra via, a Corte nacional, ao declarar a inconstitucionalidade do tratado deveria aplicar a limitação dos efeitos da declaração para que só se tenha efeito a partir da denúncia ou extinção. Essa modulação demarca então, um "pré-aviso" pelo qual a denúncia unilateral produz a extinção das obrigações do Estado denunciante decorrido tal prazo. Com isso, se geraria uma sincronia com a validade interna e a internacional (CARVALHO DE RAMOS, 2016, p. 456).

E o último ponto de dissonância nos diálogos jurisdicionais que se demonstra é o do descumprimento por ordem judicial nacional de decisões internacionais. Essa perspectiva 
dissonante de diálogo, é percebida pelo "vício de criar os "tratados internacionais nacionais" ". Desse modo, o país se expõe a responsabilização internacional por não criar mecanismos de conciliação (CARVALHO DE RAMOS, 2016, p. 456 e 457).

Outra importante contribuição doutrinária, refere-se às lições do transconstitucionalismo, de Marcelo Neves. Ensina o autor, ao tratar do transconstitucionalismo entre direito internacional público e o direito estatal, que ocorre a conversação entre ordens no Sistema Interamericano de Direitos Humanos, pelo exercício jurisdicional da Corte Interamericana de Direitos Humanos- Corte IDH, e as ordens estatais dos Estados signatários da Convenção de Direitos Humanos. Nesse ponto, aduz Marcelo Neves que entre essas duas ordens jurisdicionais tem havido "uma disposição de diálogos em questões constitucionais comuns referentes à proteção dos direitos humanos, de tal maneira que se amplia a aplicação do direito convencional pelos tribunais domésticos" (NEVES, 2009, p. 145).

Na mesma linha de raciocínio sobre a ampliação da aplicação do direito convencional pelas cortes nacionais, ensinam Jânia Saldanha e Lucas Vieira que as decisões da Corte Interamericana impulsionam o diálogo pelo exercício do controle de convencionalidade (que será estudado na segunda parte dessa pesquisa). Assim, para os autores "o impulso para a abertura e o diálogo interjurisdicional entre a Corte de San José e os Judiciários nacionais, principalmente no que tange à ampliação dos cânones jurisprudenciais protetivos dos direitos humanos, é extraordinário" (SALDANHA e VIEIRA, 2014, p. 17).

De outra banda, necessário se faz apresentar algumas considerações sobre a prática dos diálogos jurisdicionais. Assim, esclarece-se que não se trata apenas de "conversas" formais processuais. Esses diálogos vêm ocorrendo de modo presencial, em congressos, por exemplo. Nesse ponto, é que se referem Roberto Dias e Michael Freitas Mohallem, “o fenômeno é também marcado pela consolidação de redes presenciais de cortes e juízes. Os encontros se realizam periodicamente em planos internacional e regional e estimulam a troca de informações [...]" o que de certo modo auxilia na compreensão recíproca do contexto judicial de cada Estado (DIAS e MOHALLEM, 2016, p. 383)

No mesmo intuito, Benoît Frydman ao mencionar sobre reuniões de juízes "além cortes" infere que "um espírito comum emana desses encontros e jantares, dos congressos e das salas de bate-papo [...] do qual, sabemos desempenha um papel principal na criação de identidade comuns, de redes de relacionamentos [...]", então graças a esse diálogo é que se firma a internacionalização do direito (FRYDMAN, 2016, p. 19). 
E com relação à compatibilização desse diálogo é que a ferramenta do controle de convencionalidade vêm auxiliando na harmonização da fonte internacional com a nacional de direito. Desse modo, passa-se a explorar o tema no próximo tópico.

\section{DIFUSÕES DOUTRINÁRIAS SOBRE O CONTROLE DE CONVENCIONALIDADE}

De acordo com as lições de Valerio de Oliveira Mazzuoli é possível compreender que além do tradicional controle de constitucionalidade, deve haver o "controle de convencionalidade das leis, que é a compatibilização da produção normativa doméstica com os tratados de direitos humanos ratificados pelo governo e em vigor no país” (MAZZUOLI, 2013, p.5).

Na mesma linha de raciocínio, alerta Luiz Guilherme Marinoni que esse controle de convencionalidade, também denominado de controle de compatibilidade, deve ser exercido em duas vias: a primeira vertente é a do juiz nacional, a requerimento da parte ou de ofício, o que se denomina de caráter difuso. E a segunda via é por parte da Corte Interamericana de Direitos Humanos em face do Pacto, o que se chama de caráter concentrado (MARINONI, 2013, p. 66 e 71).

E conectando a utilização do controle de convencionalidade e suas vertentes com os diálogos jurisdicionais, observa-se o ponto comum entre os temas. $\mathrm{O}$ viés de controle exercido pelo juiz nacional frente à Corte, seria o diálogo jurisdicional vertical "de baixo para cima". Por sua vez, o controle exercido pela Corte frente à jurisdição interna, seria o diálogo jurisdicional vertical "de cima para baixo".

Retomando sobre o controle de convencionalidade, a doutrina chilena de Humberto Nogueira Alcalá também conceitua o controle de convencionalidade e apresenta que esse controle deve ser feito pelos juízes nacionais. Assim, afirma o autor, a partir de tradução livre, que "o exercício do controle de convencionalidade praticado pelos juízes nacionais implica em confrontar que as normas internas não vulnerem as regras determinadas pelo direito convencional" ${ }^{\prime 331}$ (ALCALÁ, 2013, p.482).

\footnotetext{
${ }^{331}$ No original em Espanhol: "el ejercicio del control de convencionalid que deben practicar los jueces domésticos implica confrontar [...] que las normas internas no vulneran las reglas determinadas por el derecho convencional internacional o supranacional em su caso" (ALCALÁ, 2013, p.482).
} 
Historicamente, a primeira vez que foi mencionado a expressão controle de convencionalidade, ocorreu na decisão do caso Myrna Mack Chang vs. Guatemala (CORTE IDH, 2003).

Entretanto, foi no caso Almonacid Arellano vs. Chile que se obtém o conceito de convencionalidade e as primeiras aproximações do tema. Assim, nas expressões da sentença do caso Almonacid Arellano vs. Chile, proferida pelo então presidente da Corte, o Juiz Sergio García Ramírez, restou confirmado, por uma tradução livre, que “o Poder judiciário deve exercer uma espécie de 'controle de convencionalidade' entre as normas jurídicas internas que aplicam em casos concretos e a Convenção Americana sobre Direitos Humanos [...]"332. O que decorre disso é que o Poder Judiciário deve exercer além do controle frente à Convenção, deve atentar como interpreta a Corte, vez que é a intérprete última das normas convencionais (CORTE IDH, 2006, p. 53).

Dessa forma, merece destaque as lições do professor Ingo Wolfgang Sarlet, pois o autor infere que esse não é um controle exclusivamente jurisdicional. Nas palavras dele: "O Poder Legislativo, quando da apreciação de algum projeto de lei, [...], também deveria assumir como parâmetro os tratados internacionais" e segue auferindo que a análise de compatibilidade deve ser levada ainda mais a sério quando versar sobre tratados de direitos humanos (SARLET, 2013, p. 112).

Sobre a importância em resultados do controle de convencionalidade, Flávia Piovesan disserta que "o controle de convencionalidade contribuirá para que se implemente no âmbito doméstico os standards, princípios, normatividade e jurisprudência internacional em matéria de direitos humanos" (2013, p. 142), mas ressalta-se que essa contribuição somente será materializada se as cortes nacionais, como o Supremo Tribunal Federal forem receptivas a esse controle que é considerado temática recente nos estudos jurídicos.

A respeito da receptividade pelas cortes nacionais, Flávia Piovesan afirma que ainda é escassa no Brasil a jurisprudência do Supremo Tribunal Federal que implementa a jurisprudência da Corte Interamericana, ao passo que é mais expressivo os julgados que rementem aos órgãos jurisdicionais internacionais como a Suprema Corte dos Estados Unidos da América e ao Tribunal Constitucional Alemão (PIOVESAN, 2013, p. 138 e 139).

\footnotetext{
332 No original em Espanhol: "el Poder Judicial debe ejercer una especie de "control de convencionalidad" entre las normas jurídicas internas que aplican en los casos concretos y la Convención Americana sobre Derechos Humanos [...]" (CORTE IDH, 2006, p. 53).
} 
Na mesma linha de raciocínio, Eduardo Appio corrobora com a temática de que no Brasil ainda é pouco exercido o controle de convencionalidade ao anunciar que é preciso a ocorrência de dois pressupostos para a internalização dos direitos humanos. O primeiro pressuposto refere que os Estados-nacionais aceitem órgãos jurisdicionais externos para que controlem "o cumprimento efetivo do dever de adesão às cláusulas previstas no tratado ou convenção internacional sobre direitos humanos", e o segundo pressuposto indica que as próprias vítimas- titulares dos direitos violados- busquem o socorro internacional a esses órgãos, caso no país seja insuficiente a tutela (APPIO, 2013, p. 186).

E ainda, Eduardo Appio, em sintonia com os ensinamentos de Flávia Piovesan, indica que os juízes brasileiros "não têm realizado o controle de convencionalidade em seus julgamentos" e de que isso decorre em "erros de julgamento em determinados casos". Pois, os juízes nacionais "não têm considerado as convenções internacionais sobre direitos humanos como fonte formal e material de Direito para as suas decisões" (APPIO, 2013, p. 186, 210 e 211).

Desse modo, é possível recordar-se da primeira parte da pesquisa, quando se tratou dos aspectos dissonantes dos diálogos jurisdicionais. E essa não aplicação do dever de adesão das cláusulas convencionais, bem como a não utilização das normas convencionais para a interpretação das decisões nacionais, referidas por Appio, são exemplos da dissonância nos diálogos jurisdicionais com relação ao controle de convencionalidade.

E assim, como uma provável solução a esse desafio de implementação efetiva de controle de convencionalidade no país, é que Flávia Piovesan traz ao debate que é preciso fomentar uma cultura jurídica orientada pelo controle de convencionalidade. Essa fomentação, indica a autora, deve ir além da ratificação do tratado internacional de direitos humanos no âmbito doméstico e a concessão de seu status de emenda constitucional. Esse incremento deve "transformar a cultura jurídica tradicional, por vezes refratária e resistente ao Direito Internacional, a fim de que realize o controle de convencionalidade" (PIOVESAN, 2013, p. 141).

Com relação aos efeitos que o controle de convencionalidade exerce nas jurisdições internas, é possível apresentar o efeito de inconvencionalidade da lei. Nesse sentido, escreve sobre esse efeito a doutrina argentina de Calogero Pizzolo, a partir de uma tradução livre, que “o controle de convencionalidade tem então como efeito a 'inconvencionalidade'- isto é, a falta de validade, de uma norma assim desqualificada por carecer desde o início de efeitos 
jurídicos"333 (2013, p. 436). Isso significa que uma norma que tem sua validade atacada não deve ser objeto de aplicação, por isso a importância desse controle.

Outro efeito que precisa ser valorado refere-se ao artigo segundo da Convenção Americana de Direitos Humanos. Nesse artigo fica estabelecido para os Estados-nações que tenham ratificado seu texto que é dever do Estado de adotar disposições de direito interno que ainda não estejam garantidas por esses Estados-partes. E ainda, se ressalta do teor do dispositivo que a norma deve estar de acordo com as normas constitucionais dos Estados e de acordo com as disposições da Convenção.

Desse modo, no caso do Brasil, o Estado promulgou o decreto-lei ${ }^{\circ} 678$, de 6 de novembro de 1992, para ratificar e aderir à Convenção Americana, sendo que as únicas ressalvas feitas no ato dessa adesão, foram com relação aos artigos 43 e 48, alínea d, que não incluem visitas automáticas da Comissão Interamericana no país. Logo, o Brasil aceitou o teor do dispositivo segundo da Convenção que indica que os Estados, caso não tenham legislações em defesas dos direitos citados nela, devem adequar sua produção normativa de acordo com suas normas constitucionais e convenção, exercendo o controle de convencionalidade, então (BRASIL, 1992).

Sobre isso, volta-se aos ensinamentos da doutrina chilena de Humberto Nogueira Alcalá no sentido de que "essa realidade jurídica implica que os Estados-partes se encontrem obrigados a respeitar e garantir os direitos assegurados convencionalmente" 334 , a partir de tradução livre. E ainda, afirma o autor que essa obrigação de respeito à convenção deve ser exercida pelos seus órgãos e agentes do Estado. E quando o caso está no sistema interamericano de proteção é porque a jurisdição interna falhou, uma vez que só se chega a esse sistema, após esgotamento de vias internas (ALCALÁ, 2013, p.478 e 479).

Outra decorrência da aplicação do controle de convencionalidade que merece ser mencionada trata da transformação de paradigmas para controle, mudança de standards mínimos para proteção dos direitos humanos, o que acarretaria em um fomento do direito constitucional comum, especificadamente no sistema regional interamericano.

Nas palavras de Humberto Nogueira Alcalá, a partir de tradução livre ${ }^{335}$ :

\footnotetext{
${ }^{333}$ No original em Espanhol, "el control de convencionalidad tiene entonces como efecto la 'inconvencionalidad'esto es la falta de validez, de una norma así descalificada, por carecer desde un inicio de efectos jurídicos" (PIZZOLO, 2013, p.436)

${ }^{334}$ No original em Espanhol, "esta realidad jurídica que implica que los estados partes se encuentranen la obligación de respetar y garantizar los derechos assegurados convencionalmente" (ALCALÁ, 2013, p. 478)

${ }^{335}$ No original em Espanhol: "El control de convencionalidad deposita en sede jurisdiccional nacional un voto de confianzaen que los juezes locales interpretán el derecho de los derechos humanos contribuyendo generar um
} 


\begin{abstract}
O controle de convencionalidade deposita em sede jurisdicional nacional um voto de confiança em que os juízes locais interpretem os direitos humanos, contribuindo para gerar um direito público comum básico de nível regional interamericano, reforçando o Estado Constitucional democrático na região, uma melhor proteção dos direitos fundamentais das pessoas, um direito público regional mais integrado ao menos em standards mínimos de respeito dos direitos humanos [...] (ALCALÁ, 2013, p. 500).
\end{abstract}

Nesse sentido, com o efetivo exercício do controle de convencionalidade o que se visualiza como efeito marcante é a maior valorização dos direitos humanos, com a presença de padrões mínimos de proteção de direitos humanos a serem tutelados pelos Estados, no caso dos Estado do Sistema Interamericano.

Ainda, como implicação do controle de convencionalidade é possível se verificar o diálogo jurisprudencial. Reforçando a ideia, a jurisprudência nacional interage com a jurisprudência convencional. Nesse aspecto, convém inferir a doutrina mexicana de Eduardo Ferrer Mac-Gregor que estabelece que a medida que essas interações vão acontecendo, entre as jurisprudências, ambas as jurisdições devem atender à normatividade nacional e convencional. E conforme o Mac-Gregor, esse estreitamento "dos vasos comunicantes" desse diálogo cria uma ferramenta de dupla via. O Estado que utiliza em sua jurisprudência nacional o controle de convencionalidade "sintoniza-se" com o sistema de proteção internacional, a partir dos já citados standards mínimos, e a corte nacional deixa ter o monopólio da interpretação dos direitos humanos. E de outra banda, a Corte Interamericana enriquece sua jurisprudência e fortalece a vigência dos direitos humanos da Convenção Americana (MAC-GREGOR, 2013. p. 651,653 e 655$)$.

Dessa maneira, superada essa etapa das difusões doutrinárias sobre o controle de convencionalidade, passa-se a abordar acerca da sincronização dos diálogos jurisdicionais com a temática do controle.

\title{
4 ALINHAMENTO ENTRE OS DIÁLOGOS JURISDICIONAIS E O CONTROLE DE CONVENCIONALIDADE - ALGUMAS INQUIETAÇÕES SOBRE O TEMA
}

derecho público común básico de nivel regional interamericano, reforzando el Estado Constitucional democrático en la región, una mejor protección de los derechos fundamentales de las personas, um derecho público regional mas integrado al menos em los estándares mínimos de respecto de derechos humanos [...] (ALCALÁ, 2013, p. 500). 
Relembrando os modelos de diálogos jurisdicionais, enfoca-se no modelo vertical, da Corte Interamericano e as jurisdições nacionais constitucionais latino-americanas. Nesse ponto, conforme infere Víctor Bázan, é crescente a intensidade com que se desenvolve a dinâmica interativa do direito interno com o direito internacional dos direitos humanos e isso acentua a necessidade de se lograr a existência pacífica de tais fontes, a fim de que se solidifique o sistema regional de proteção dos direitos humanos e de que se zele, pelo efetivo cumprimento dos Estados, os tratados firmados internacionalmente, por uma tradução livre ${ }^{336}$ (BÁZAN, 2014, p. 424)

Ainda, alerta o argentino Víctor Bázan que com essa necessidade de convivência pacífica entre o interno e o interamericano aspira-se que se acentue o processo de sinergia e fertilização cruzada (diálogo jurisdicionais) sustentável e equilibrado, movido por uma verdadeira vontade política. E ainda, que o diálogo seja crítico que se converta realmente em potenciais evoluções na luta de proteção dos direitos humanos, por uma tradução livre ${ }^{337}$ (BÁZAN, 2014, p. 426)

Cabe também mencionar os ensinamentos de Marie-Claire Ponthoreau, nesse sentido, a autora explica sobre o "universalismo limitado", ao aduzir que há uma dificuldade de concretização no diálogo dos juízes que parte da sua essência da comunicação, qual seja: a linguagem. Para a autora a denominação diálogo de juízes está prejudicada pelo fato de que muitas vezes, por obscuridades linguísticas, esse diálogo não ocorre (PONTHOREAU, 2014, p. 16).

No entanto, alerta a autora que cada vez mais vão se buscando soluções para esse problema no direito constitucional transnacional, uma vez que as decisões estão disponíveis em tradução em vários idiomas, como exemplo as decisões da Corte Interamericana traduzidas para o Inglês. Nesse ponto, recorda-se do início da pesquisa quando Delmas-Marty, traz a ideia de que a intensificação da internacionalização do direito se dá pelas novas tecnologias, o que auxilia nessas soluções idiomáticas. Assim, como infere Marie-Claire Ponthoreau, o trabalho

\footnotetext{
${ }^{336}$ Do original em Espanhol "La creciente intensidad con que se desenvuelve la dinámica interactiva del derecho interno y el derecho internacional de los derechos humanos acentúa la exigencia de lograr una pacífica articulación de tales fuentes en aras de solidificar el sistema general de derechos y pugnar por el cumplimiento por el Estado de los compromisos internacionalmente asumidos en la materia." (BÁZAN, 2014, p. 424)

${ }^{337}$ Do original em Espanhol: "En prospectiva, aspiramos a que entre las jurisdicciones internas y la interamericana se acentúe un proceso de sinergia y fertilización cruzada sustentable, equilibrado y movido por una verdadera voluntad política. Ojalá germine entre aquellas un diálogo crítico y tangible que convierta en realidad sus potencialidades evolutivas y las vuelque en la lucha porla protección de los derechos humanos[...]" (BÁZAN, 2014, p. 426)
} 
está longe de terminar, mas essa transformação coletiva segue avançando (PONTHOREAU, 2014, p. 17)

No mais, importante inferir as lições de Jânia Saldanha e Márcio Brum, no sentido que existem desafios às jurisdições para pensarem o múltiplo, conforme palavras dos autores "a busca de um direito comum universalista e pluralista apresenta às jurisdições o desafio de pensarem o múltiplo, de forma a harmonizá-lo, através de uma lógica de compatibilidade" (SALDANHA e BRUM, 2015, p. 232).

E essa lógica de compatibilidade vai desde o desenvolvimento do diálogo crítico entre jurisdições e a aplicação efetiva do controle de convencionalidade para a internacionalização do direito, e com isso a concretização de proteção por standards mínimos de direitos humanos. Assim, ao se encaminhar para o fim da presente pesquisa, apresenta-se os desafios às jurisdições na contemporaneidade, conforme ensina Flávia Piovesan.

Assim, com a finalidade de efetivar o piso mínimo protetivo de direitos humanos é que Flávia Piovesan lista sete desafios para o fortalecimento dos diálogos entre jurisdições: 1 . Promoção da ampla ratificação de tratados internacionais de direitos humanos; 2. Fortalecimento da incorporação nas legislações internas de tratados de direitos humanos com status privilegiado; 3. Fomentação da cultura jurídica orientada pelo controle de convencionalidade; 4. Fomentação de programas de capacitação para que os Poderes (Executivo, Legislativo e Judiciário) apliquem parâmetros internacionais protetivos de direitos humanos; 5. Dinamização dos diálogos entre os sistemas regionais; 6. Aprimoramento de mecanismos de implementação de decisões internacionais no âmbito interno e 7. Dinamização do diálogo entre jurisdições constitucionais (PIOVESAN, 2012, p. 89-92).

Dessa forma, fica evidenciada que a sincronização das ideias de diálogos jurisdicionais com o efetivo exercício do controle de convencionalidade é ferramenta que não se pode mais ignorar em tempos de neoconstitucionalismo. Isso pois, esses institutos se complementam enquanto mecanismos de tutela dos direitos humanos cada vez mais presentes no processo da internacionalização do direito.

\section{CONSIDERAÇÕES FINAIS}

Da permeabilidade do direito, enquanto característica do neoconstitucionalismo, surgem os diálogos jurisdicionais que conforme observado no início dessa pesquisa podem ocorrer em 
diversos sentidos. Há diálogos horizontais, entre Cortes nacionais, e diálogos verticais entre Corte Internacionais e Cortes nacionais. Também existem os diálogos cruzados, entre Cortes internacionais de matérias diferentes, como de direitos humanos e direito comercial, por exemplo.

A presente pesquisa acolheu a perspectiva do diálogo jurisdicional vertical entre a Corte Interamericana de Direitos Humanos e as jurisdições nacionais latino-americanas. Nesse ponto, verificou-se que com os diálogos há aspectos harmônicos e dissonantes que permeiam o assunto. Assim, inseriu-se a temática do controle de convencionalidade a fim de que se zele pela harmonização das normas convencionais com as nacionais.

Desse modo, observou-se que o controle de convencionalidade não é exclusividade do Poder Judiciário, e outros poderes devem fomentar a cultura jurídica para o exercício desse controle. Isso pois, com os diálogos jurisdicionais, entre Corte Interamericana e jurisdições nacionais, por vezes decorre em incompatibilidade de fontes.

Dessa forma, apresentou-se os desafios que as jurisdições na contemporaneidade têm que enfrentar para efetivação de tutela dos standards mínimos protetivos de direitos humanos em tempos de internacionalização do direito.

Por fim, mister indicar que como o neoconstitucionalismo é um movimento, as implicações resultantes dele não são estanques. Assim, verifica-se que esses diálogos jurisdicionais e o controle de convencionalidade são parte desse movimento que ainda se adequam com o passar do tempo. Entretanto, visualiza-se que os primeiros passos a fim da harmonização já foram iniciados, necessário se faz continuá-los.

\section{REFERÊNCIAS}

APPIO, Eduardo. Os juízes e o controle de convencionalidade no Brasil. In: MAZZUOLI, V. O.; MARINONI; L. G. (Cords.). Controle de convencionalidade: um panorama latinoamericano. Brasília: Gazeta Jurídica, 2013, p.181-212

ALCALÁ, Humberto Nogueira. Los desafios del control de convencionalidaddel corpus iuris interamericano para los tribunales nacionales y su deferenciaciación com el control de convencionalidad. Controle de convencionalidade: um panorama latino americano. Brasília: Gazeta Jurídica, 2013, p.465-544

BAZÁN, Víctor. Vinculatoriedad de los estándares interpretativos de la Corte Interamericana de Derechos Humanos en los órdenes internos, control de convencionalidad y diálogo 
jurisprudencial. In: Anuario de derecho constitucional latinoamericano, v. 20, p. 385-429, 2014. Disponível em:

<http://spij.minjus.gob.pe/content/publicacion_extranjera/repositorio/convencion/ANUARIO 2014.pdf\#page=742>. Acesso em: 22 de jul. 2016.

BRASIL. Constituição (1988). Constituição da República Federativa do Brasil: promulgada em 5 de outubro de 1988. Diário Oficial da República Federativa do Brasil, Brasília, DF, 6 out. 1988. Disponível em:

<http://www.planalto.gov.br/ccivil_03/constituicao/constituicao.htm>. Acesso em: 20 jul. 2016.

Decreto $n^{\circ}$ 678, de 6 de novembro de 1992. Promulga a Convenção Americana sobre Direitos Humanos (Pacto de São José da Costa Rica), de 22 de novembro de 1969. Diário Oficial da União de 9 de novembro de 1992. Disponível em: <http://www.planalto.gov.br/ccivil_03/decreto/D0678.htm>. Acesso em: 22 de jul. 2016.

BURGORGUE-LARSEN, Laurence. A internacionalização do diálogo dos juízes: missiva ao Sr. Bruno Genevois, Presidente do Conselho de Estado da França-doi: In. Prismas: Direito, Políticas Públicas e Mundialização (substituída pela Revista de Direito Internacional), v. 7, n. 1, 261-304, 2010. Disponível em: <http://publicacoes.uniceub.br/index.php/prisma/article/download/1145/989>. Acesso em: 21 de jul. 2016.

CARBONELL, Miguel (ed). Neoconstitucionalismo(s). 4.ed. Madrid: Editorial Trotta, 2009.

CARVALHO DE RAMOS, André de. Realizando a convergência entre o nacional e o internacional: os círculos[...]. In PIOVESAN, Flávia; SALDANHA, Jânia Maria Lopes (Coords). Diálogos Jurisdicionais e Direitos Humanos. 1 ed. Brasília: Gazeta Jurídica, 2016, p. $437-468$

CORTE INTERAMERICANA DE DIREITOS HUMANOS (CORTE IDH). Caso Almonacid Arellano y otros vs. Chile. Excepciones preliminares. Fondo, Reparaciones y Costas. Sentencia de 26 set. 2006. Serie C No. 154. Disponível em:

<http://www.corteidh.or.cr/docs/casos/articulos/seriec_154_esp.pdf >. Acesso em: 21 de jul. 2016.

Caso Myrna Mack chang vs. Guatemala. Fondo, Reparaciones y Costas. Sentencia de 25 nov. 2003. Serie C No. 101. Disponível em: <http://www.corteidh.or.cr/docs/casos/articulos/seriec_101_esp.pdf $>$. Acesso em: 21 de jul. de 2016. 
DELMAS-MARTY, Mireille. La Refondation des Pouvoirs. Paris: Seuil, 2007

DIAS, Roberto; MOHALLEM, Michael Freitas. In PIOVESAN, Flávia; SALDANHA, Jânia Maria Lopes (Coords). Diálogos Jurisdicionais e Direitos Humanos. 1 ed. Brasília: Gazeta Jurídica, 2016, p. 348-383

FRYDMAN, Benoît. Diálogo internacional dos juízes e a perspectiva ideal de justiça universal. In: PIOVESAN, Flávia; SALDANHA, Jânia Maria Lopes (Coords). Diálogos Jurisdicionais e Direitos Humanos. 1 ed. Brasília: Gazeta Jurídica, 2016, p. 15-38

MARINONI, Luiz Guilherme. Controle de convencionalidade (na perspectiva do direito brasileiro). In: MAZZUOLI, V. O.; MARINONI; L. G. (Cords.). Controle de convencionalidade: um panorama latinoamericano. Brasília: Gazeta Jurídica, 2013, p.57-86

MAC-GREGOR. Eduardo Ferrer. Interpretación conforme y control difuso de convencionalidade elnuevo paradigma para eljuez mexicano. In: MAZZUOLI, V. O.; MARINONI; L. G. (Cords.). Controle de convencionalidade: um panorama latinoamericano. Brasília: Gazeta Jurídica, 2013, p.547-656

MAZZUOLI, Valerio de Oliveira. Teoria geral do controle de convencionalidade no direito brasileiro. In: MAZZUOLI, V. O.; MARINONI; L. G. (Cords.). Controle de convencionalidade: um panorama latinoamericano. Brasília: Gazeta Jurídica, 2013,p. 4-56

NEVES, Marcelo. Transconstitucionalismo. São Paulo: WMF Martins Fontes, 2009.

PIOVESAN, Flávia. Controle de convencionalidade direitos humanos e diálogo entre jurisdições. In: MAZZUOLI, V. O.; MARINONI; L. G. (Cords.). Controle de convencionalidade: um panorama latinoamericano. Brasília: Gazeta Jurídica, 2013, p. 115146

. Diálogo no Sistema Interamericano de Direitos Humanos: desafios da reforma. In:

Campo Jurídico, v. 1, n. 1, p. 163-186, 2013. Disponível em:<http://fasb.edu.br/revista/index.php/campojuridico/article/view/11/14>. Acesso em $20 \mathrm{de}$ jul. 2016

Direitos humanos e diálogo entre jurisdições. In: Revista brasileira de direito constitucional, v. 19, n. 1, p. 67-93, 2012. Disponível em: <http://www.esdc.com.br/seer/index.php/rbdc/article/view/176/170>. Acesso em 25 de jul. 2016 
PIZZOLO, Calogero. Efectos de ladoctrina sobre elcontrol de convencionalidad de acuerdoconlos precedentes de la Corte Suprema de Justicia argentina. In: MAZZUOLI, V. O.; MARINONI; L. G. (Cords.). Controle de convencionalidade: um panorama latinoamericano. Brasília: Gazeta Jurídica, 2013, p. 427-448

PONTHOREAU, Marie-Claire. Le recours aux précédents étrangers par le juge constitutionnel. p. 1-17, 2014. Disponível em:

<http://www.iacl2014congress.com/fileadmin/user_upload/k_iacl2014congress/General_repo rts/Ponthoreau-RapportFR.pdf>. Acesso em 22 de jul. 2016

ROTHENBURG, Walter Claudius. Diálogo internacional entre juízes: a influência do direito estrangeiro e do direito internacional na solução de casos de direitos fundamentais. In:

MARINHO, Maria Edelvacy; TELES DA SILVA, Solange; OLIVEIRA, Liziane Paixão

Silva (Org). Diálogos entre juízes. Brasília: UniCEUB, 2014, p. 39-55

SALDANHA, Jânia Maria Lopes; VIEIRA, Lucas Pacheco. Modelos de controle de convencionalidade sob uma perspectiva otimizadora. In: Libertas, v. 1, n. 1, 2014. Disponível em: <http://www.libertas.ufop.br/index.php/libertas/article/view/9>. Acesso em 21 de jul. 2016

.; BRUM, Márcio Morais. A margem nacional de apreciação e sua (in) aplicação pela Corte Interamericana de Direitos Humanos em matéria de anistia: uma figura hermenêutica a serviço do pluralismo ordenado?. Anuario mexicano de derecho internacional, v. 15, n. 1, p. 195-238, 2015. Disponível em:

<http://www.sciencedirect.com/science/article/pii/S1870465415000070>. Acesso em 25 de jul. 2016

SARMENTO, Daniel. O Direito Constitucional e o Direito Internacional: diálogos e tensões. In: PIOVESAN, Flávia; SALDANHA, Jânia Maria Lopes (Coords). Diálogos Jurisdicionais e Direitos Humanos. 1 ed. Brasília: Gazeta Jurídica, 2016, p. 93-138

SARLET, Ingo Wolfgang. Notas sobre as relações entre a Constituição Federal de 1988 e os tratados internacionais de direitos humanos na perspectiva do assim chamado controle de convencionalidade. In: MAZZUOLI, V. O.; MARINONI; L. G. (Cords.). Controle de convencionalidade: um panorama latinoamericano. Brasília: Gazeta Jurídica, 2013, p. 87114

JURISDICTIONAL DIALOGUES AND CONVENTIONALITY CONTROL: CHALLENGES TO THE HARMONIZATION OF THE DIALOGUE BETWEEN THE 


\title{
INTER-AMERICAN COURT OF HUMAN RIGHTS AND THE LATIN AMERICAN NATIONAL JURISDICTIONS IN TIMES OF NEOCONSTITUTIONALISM
}

\begin{abstract}
This research addresses the challenges of harmonizing the judicial dialogue between the Inter-American Court of Human Rights and the national jurisdictions of Latin America in the context of neoconstitutionalism. For that, the method of hermeneuticphenomenological approach was chosen, since with the incursion of the interpreter into the phenomenon occurs the understanding. Thus, the phenomena studied are the dialogues between the Inter-American Court and the national jurisdictions with the convention control mechanism in this conversation. Thus, as a procedure is adopted the bibliographic and documentary review. Also, the research is divided into three phases, the first one will assess the contextual aspects, as well as the conceptualization of jurisdictional dialogues and the harmonizing and dissonant perspectives of these dialogues. In the second stage, the doctrinal contributions about the control of conventionality are listed, thus seeking the lessons of Humberto Nogueira Alcalá, Eduardo Ferrer Mac-Gregor, Valerio Mazzuoli, Flávia Piovesan, among others. And in the last stage, it is presented the alignment of the ideas of the jurisdictional dialogues and the control of conventionality as a tool of harmonization between internal and conventional sources, and also, what the remaining challenges to the effective control of the dialogues, in the period of internationalization of the law.
\end{abstract}

Keywords: Jurisdictional dialogues. Conventionality control. Neoconstitutionalism. 